\title{
Study on Accounting Management under Big Data Era
}

\author{
Biao Liü, a \\ ${ }^{1}$ Jiangxi Science \& Technology Normal University, Finance Department, Nanchang, Jiangxi, \\ 330013 \\ a email
}

Keywords: The Era of Big Data, Accounting Management, Effective Strategies

\begin{abstract}
In the big data era background, and other daily production, operation and management activities of the project company are developing a greater degree of change. From the perspective of business management accounting point of view, in large data background, which affected it is significant. The views from the analysis of potential accounting issues under the management of big data era background, further based on an effective strategy to strengthen the accounting management of large data background to explore, in order to optimize business accounting management and improve to provide some recommendations have value.
\end{abstract}

\section{Introduction}

In the 21st century, in the context of the era of big data, mobile Internet is becoming the axis began development of the Internet. Development of large data, is affecting people's daily life, study and work. For enterprises, the affected era of big data is also very obvious. With massive data big data, by screening and integration, can effectively improve the predictive ability of enterprises so that enterprises to seize the opportunity for development; At the same time, through some valid data, can strengthen development planning and control, thereby so that their production more efficient operational efficiency [1]. At the same time, the negative impact of big data on enterprises is particularly significant, accounting management levels of the enterprise from a single point of view, it has many problems. In order to effectively manage corporate accounting optimization and improvement, this article on the "era of big data management accounting" study is significant.

\section{Potential Problems of Accounting Management under the Background of Big Data}

In the background of big data, enterprise management accounting is affected significantly. However, for some companies, but there are large accounting data management lack of knowledge of the situation. On the one hand, some SMEs lack of knowledge of Big Data technology, saw the introduction of big data technology or R \& D needs to invest a lot of manpower, material and funds for SMEs, which will bring huge burden, thus ignoring the large learning to use technology or data [2]. On the other hand, some companies fail to recognize the large enterprise data management accounting convenience and opportunity for development, resulting in the accounting management work, big data application efficiency is not high, which to some extent inhibited the enterprise development of accounting management.

Accounting management is a very important work which carrying out the management of accounting, if you need vast amounts of information collection, collation, it will involve a lot of personal or corporate secret information. For these secret information, in its safety be effectively guaranteed a prerequisite to be able to enable enterprises to efficiently use this information to start data corresponding work, so as not to cause leakage of information, and further avoid security problems development of. However, at present, most of the enterprises in terms of information security and accounting management also seems to be rather weak. Obviously, this is the development of the next era of big data business is extremely unfavorable.

Accounting management, and accounting management plays a very important role. To make the accounting management of enterprises to adapt to the development of big data era, would be necessary to improve the quality of accounting personnel management [3]. But the current situation, 
the quality of corporate accounting manager has yet to be improved. On the one hand, the performance of management accounting in large data knowledge is weak; on the other hand, the performance of accounting management personnel in the use of data, the ability to practice the management of the weak. In short, at the low quality of management accounting, the accounting will make the management of the enterprise is difficult to effectively progress and development.

\section{Effective Strategies of Accounting Management based on the Large Data Background}

To make the accounting management under the era of big data business effectively strengthened, first there will be a need to strengthen corporate accounting management of large data awareness. On the one hand, companies need to organize big data relevant personnel involved in the study of knowledge, so that all parties will recognize the business impact of big data on enterprise development brings. Especially for accounting management personnel, the need by learning to recognize the positive impacts and negative impacts on the accounting management of large data brought, thereby enhancing the sense of responsibility accounting management personnel [4]. On the other hand, companies need to recognize that Big Data in the important role of information technology on the basis of a reasonable increase in capital investment, learning and the introduction of big data technology, as a rational management of corporate accounting, scientific application of big data to provide effective support , further accounting management of companies effectively optimize and improve.

From the current situation, some enterprises, especially SMEs, accounting management information analysis technology yet insufficient. This issue will greatly restrict the background to optimize large data and accounting management of the enterprise. Therefore, it is necessary to strengthen the accounting management information analysis system construction. On the one hand, to ensure that the information storage optimization tools to ensure that they have a strong capacity to accommodate TB level data is immediately and quickly analyze data, and low-latency data access and decision-making to give full support. On the other hand, improve the utilization of cloud computing in the enterprise accounting management, the sharing of resources by means of cloud computing, fast delivery and on-demand services, so that the accounting management of companies effectively optimize and improve. In addition, it is necessary to build their enterprise's own accounting management information analysis system, the system transfer accounting management problem analysis information to achieve early warning of accounting management of potential risks, so as to make timely and effective resolve to lay a solid foundation for further provide valid credentials for optimizing corporate accounting management.

As described above, in the background of big data, enterprise management accounting information on security seems to be rather weak. Therefore, in order to make the accounting management of enterprises to adapt to the era of big data, it would be necessary to improve security and accounting management information. On the one hand, to select cloud services providers in the process, for businesses, the need for size, service levels and the degree of credibility of the respective service providers a comprehensive analysis of the selected service providers need to consider the two elements of stability and security. For enterprises, more importantly, do the work and other investigations and risk management, to be clear on the respective service providers with risk response plan. On the other hand, the cloud computing system, it must have a data isolation so that the occurrence of illegal data available are effectively avoided [5]. At the same time occurs, we need to set the appropriate permissions for the different management staff, thereby enabling data to be tampering with or theft condition is effectively avoided. In addition, when the client application software for the user, it is necessary to encrypt the data storage and cloud computing systems also need to encrypt the data stored to give adequate support, the sharing of resources in the user select condition before allowing other users to access it. All in all, the need to enhance the security of accounting information management, further improve the management level accounting enterprises to effectively promote.

Since the accounting management work, and high participation accounting management personnel, and obviously important. Therefore, it is necessary to improve the overall quality of 
management accounting. On the one hand, business leaders need to strengthen the accounting management education, so that the accounting managers can strengthen their own learning, to learn about the impact of big data generated on the accounting management of enterprises, so that the accounting managers recognize large data background, good accounting management business importance. On the other hand, to strengthen corporate accounting management personnel training, training objectives set "Theory + Practice", that focus on large data theoretical knowledge, theoretical knowledge of accounting management of learning, but also need to focus on training in accounting management techniques, methods, so as to cultivate comprehensive high quality accounting and management talent to lay the foundation effective. In short, in the overall quality of management accounting to improve the conditions, we believe the accounting management of the enterprise will be able to effectively optimize and improve, so that the accounting management companies to follow the development of big data era.

\section{Conclusion}

By exploring this article, enterprise management accounting is by the multiple effects, which issues outstanding. Therefore, it is necessary to strengthen the management of large data accounting knowledge while doing accounting management information analysis system construction work, and to further enhance the security and accounting management accounting information and improve overall quality management. I believe the above aspects to be improved, accounting management companies will be able to be effectively improved, and further consolidate the foundation to promote the healthy development of enterprises.

\section{References}

[1] Cheng Ping. Xu Yunyun. Inventory Management era of big data cloud-based accounting business [J]. Friends of Accounting, 2015, 06: 134-136.

[2] Cheng Ping, Fan Ke. The cloud-based accounting of the Group companies overall budget management [J]. Friends of Accounting data age, 2015,18: 110-113.

[3] Liu Xingwu. affect era of big data management accounting Development [J]. Chinese suppliers theory, 2015, 16: 51-53.

[4] Shen Xianghua. research era of big data management and accounting application prospects in the path of commercial banks [J]. Financial Theory and Practice, 2015, 10: 113-115.

[5] Ma Aihua. impact of big data era Institution Accounting Management Analysis [J]. Enterprise Reform and Management, 2016, 04: 155. 